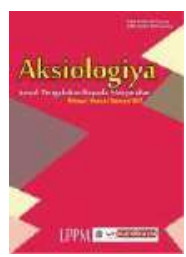

Aksiologiya: Jurnal Pengabdian Kepada Masyarakat

Vol.5, No. 1, Februari 2021 Hal 79 - 87

ISSN 2528-4967 (print) dan ISSN 2548-219X (online)

\title{
Penerapan Otomasi Perpustakaan Sekolah di Malang Raya
}

\author{
Moh. Safii ${ }^{1}$, Setiawan $^{2}$, Sokhibul Ansor³ ${ }^{3}$ Dwi Novita Ernaningsih ${ }^{4}$, Lidya \\ Amalia Rahmania ${ }^{5}$, Cicik Tri Jayanti ${ }^{6}$ \\ ${ }^{12345}$ Prodi Ilmu Perpustakaan Universitas Negeri Malang \\ ${ }^{2}$ Bahasa dan Sastra Indonesia Universitas Negeri Malang \\ Email: ${ }^{1}$ moh.safii@um.ac.id, ${ }^{2}$ setiawan@um.ac.id, ${ }^{3}$ sokhibul.ansor@um.ac.id, \\ 4dwi.novita@um.ac.id, ${ }^{5}$ lidya.amalia.fs@um.ac.id, ${ }^{6}$ jayantie19@gmail.com
}

\begin{abstract}
ABSTRAK
Berdasarkan data Kementrian pendidikan dan kebudayaan, sebanyak 34.19 persen sekolah di Indonesia dari 34 provinsi, belum memiliki perpustakaan. Padahal sesuai amanat UU No 43 Tahun 2007 hendaknya lembaga pendidikan termasuk sekolah ditunjang dengan perpustakaan. Perpustakaan tentu harus mengiringi perkembangan jaman dan mampu untuk memberikan layanan berbasis teknologi. Berdasar hal tersebut dan fakta bahwa tidak semua perpustakaan sekolah berjalan sesuai standar perpustakaan apalagi memanfaatkan otomasi perpustakaan. Maka pengabdian dalam bentuk pelatihan ini menjadi solusi dari gambaran permasalahan diatas. Metode yang digunakan dalam pengabdian ini ialah ceramah, pelatihan dan pendampingan. Diikuti oleh 34 peserta dari pengelola perpustakaan Se Malang Raya yang terdiri dari Sekolah Swasta, Sekolah Negeri, Pondok Pesantren. Saat pelatihan aplikasi otomasi perpustakaan $100 \%$ terinstall pada laptop peserta dan dapat digunakan. Sehingga pengelolaan perpustakaan yang manual sudah terbantukan dengan otomasi perpustakaan dan meninggalkan proses manual/paperbased service ke arah perpustakaan digital. Kendala yang dihadapi peserta ketika monitoring dan evaluasi ialah dukungan teknis penyediaan hardware yang belum dipenuhi oleh pihak sekolah. Saran dan tindak lanjut dari kegiatan ini ialah ditingkatkannya pada tahap lebih lanjut yaitu inovasi layanan dan akreditasi perpustakaan.
\end{abstract}

Kata kunci: otomasi perpustakaan; perpustakaan digital; perpustakaan sekolah

\section{Implementation of School Library Automation in Malang Raya}

\begin{abstract}
Based on data from the Ministry of education and culture, as many as 34.19 percents of schools in Indonesia from 34 provinces, do not yet have a library. Yet according to the mandate of Law No. 43 of 2007 educational institutions including schools should be supported by libraries. Libraries certainly have to accompany the development of the era and be able to provide technology-based services. Based on this and the fact that not all school libraries run according to library standards let alone utilize library automation. Then this service in the form of training is the solution to the picture above problems. The methods used in this service are lectures, training and mentoring. Participated in 34 participants from the library manager of Se Malang Raya consisting of Private Schools, Public Schools, Islamic Boarding Schools. During training, the library automation application is 100\% installed on the participant's laptop and can be used. So that manual library management is helped by library automation and leaves the manual / paper-based service process in the direction of digital libraries. The obstacle faced by participants when monitoring and evaluation is technical support for providing the hardware that has not been met by the school. Suggestions and follow-up from this activity are to be improved at a further stage, namely service innovation and library accreditation.
\end{abstract}

Keywords: library automation; digital library; school library 


\section{PENDAHULUAN}

Perpustakaan

berfungsi

sebagai taman bacaan, sumber-sumber belajar untuk menumbuhkan daya baca siswa yang semakin tahun semakin menurun(Safii, Zen, \& Mayesti, 2018). Peran perpustakaan tersebut tercantum dalam UU No 47 tahun 2007 tentang Perpustakaan. Secara jelas dalam UU tersebut perpustakaan harus menyediakan koleksi atau bahan yang tujuannya salah satunya untuk sarana menunjang pendidikan dan pembelajaran. Pendidikan yang berkualitas tentu ditunjang dengan lengkapnya sarana dan prasarana perpustakaan sekolah, yang tentu pustakawan juga menjalankan fungsinya dengan baik(Dewi \& Suhardini, 2014). Salah satu kebijakan pemerintah tentang pendidikan adalah peningkatan kualitas sekolah. Secara umum kegiatan belajar- mengajar di sekolah meliputi teori dan praktik. Salah satu hal yang perlu dipersiapkan untuk menunjang keberhasilan pelaksanaan pembelajaran di sekolah adalah keberadaan perpustakaan sekolah yang berfungsi secara baik. Dalam penerapan pembelajaran banyak ditemuiberbagaipermasalahan lapangan salah satunya adalah ketersediaan bahan pelajaran untuk menunjang proses pembelajaran masih harus perlu dispersiapkan dengan baik. Banyak sekolah yang belum siap dengan penyediaan bahan pelajaran melalui perpustakaan sekolah. Ketidaksiapan tersebut bukan semata-mata disebabkan kurangnya bahan pelajaran (baca buku dan sumber informasi ilmiah lainnya), akan tetapi juga disebabkan oleh pengelolaan perpustakaan yang kurang baik dan terstandar, sehingga koleksi yang sudah dimiliki kurang dapat didayagunakan untuk menunjang pelaksanaan kurikulum secara maksimal (Hanafiyah, 2018). Untuk menjembatani hal tersebut perpustakaan perlu dikelola dengan berbasis pada teknologi informasi.

Pada suatu jejak pendapat media cetak menyatakan bahwa harapan dari keberadaan perpustakaan baik itu perpustakaan umum, perpustakaan sekolah maupun perpustakaan daerah paling tidak adalah untuk membangkitkan apresiasi terhadap buku sehingga dapat membangkitkan tumbuhnya minat baca. Akan tetapi dari hasil jejak pendapat tersebut menyebutkan bahwa $51,1 \%$ paling tidak seminggu sekali berkunjung ke perpustakaan, sementara sebesar $26,7 \%$ menyatakan sebulan antara 1 sampai 3 kali, dan sebanyak 22,2\% menyatakan kurang dari satu kali sebulan atau tidak pernah. Jejak pendapattersebutmenunjukkan bahwa apresiasi terhadap perpustakaan, dalam hal ini termasuk siswa sangat rendah. Hal ini disebabkan perpustakaan kurang dapat berperan secara aktif untuk merangsang siswa agar mau datang ke perpustakaan sekolah (Vidiyawati, 2017).

Untuk meningkatkan keberadaan perpustakaan sekolah di lingkungan sekolah agar dapat berfungsi dengan baik dalam menunjang proses pembelajaran di sekolah, solusi yang perlu ditempuh adalah adanya upaya untuk 
menyiapkan sumber daya manusia yang menguasai dan peduli terhadap pengembangan perpustakaan sekolah (Nahrowi, 2016). Untuk itu dipandang strategis bahwa guru atau staf yang akan diberi tugas mengelola perpustakaan sekolah dibekali dengan pelatihan tentang manajemen dan tata kerja perpustakaan sekolah. Dengan demikian diharapkan bekal yang akan diberikan melalui pelatihan dapat diterapkan untuk menghidupkan keberadaan perpustakaan sekolah sehingga mampu menunjang kegiatan proses pembelajaran secara maksimal (Umar, 2013).

\section{METODE PENELITIAN}

Metode yang digunakan dalam pengabdian ini ialah berbentuk pelatihan aplikasi otomasi perpustakaan sesuai dengan standar perpustakaan. Pelatihan atau workshop diberikan kepada peserta dan diwajibkan untuk hadir dengan membawa laptop. Aplikasi dan materi diberikan kepada peserta untuk memudahkan saat pelatihan. Selain pelatihan, menggunakan metode ceramah dan pendampingan. Urutan pengabdian yang digunakan dalam membantu mitra pengelola perpustakaan sekolah secara umum seperti bagan berikut

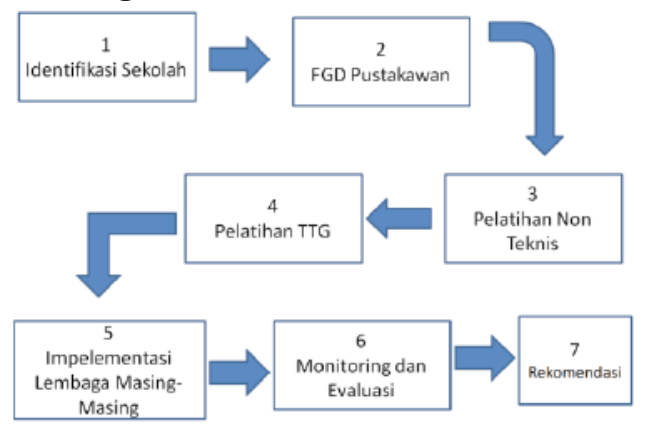

Bagan 1. Alur proses pengabdian
Bagan tersebut merupakan aliran kegiatan sebelum dan sesudah dilaksanakan pengabdian masyarakat. Satu bulan sebelum penyelenggaraan telah disebar pamflet pengabdian melalui grup whatsapp. Alur bagan tersebut digunakan untuk menjaga keterukuran hasil pengabdian dan ketepatan implementasi di perpustakaan.

\section{HASIL DAN PEMBAHASAN Identifikasi Sekolah}

Pengelola perpustakaan sekolah yang ikut serta dan diundang dalam kegiatan pelatihan ialah pengelola perpustakaan yang belum pernah mendapatkan pelatihan sejenis sebelumnya. Total sekolah yang ikut dalam pelatihan ini berjumlah 34 sekolah dengan rincian sebagai berikut

Tabel 1 Peserta Pelatihan

Berdasarkan Wilayah

\begin{tabular}{|l|c|}
\hline Asal Sekolah & $\begin{array}{c}\text { Jumlah Peserta } \\
\text { (orang) }\end{array}$ \\
\hline Kota Malang & 11 \\
\hline Kabupaten Malang & 20 \\
\hline Kota Batu & 1 \\
\hline Bangil & 2 \\
\hline
\end{tabular}

Tabel 2 Peserta Pelatihan

Berdasarkan Jenis Lembaga

\begin{tabular}{|l|c|}
\hline Asal Sekolah & $\begin{array}{c}\text { Jumlah Peserta } \\
\text { (orang) }\end{array}$ \\
\hline Perpustakaan SD & 4 \\
\hline $\begin{array}{l}\text { Perpustakaan } \\
\text { SMP }\end{array}$ & 10 \\
\hline $\begin{array}{l}\text { Perpustakaan } \\
\text { SMA }\end{array}$ & 13 \\
\hline Perpustakaan PT & 1 \\
\hline $\begin{array}{l}\text { Perpustakaan } \\
\text { Pondok } \\
\text { Pesantren }\end{array}$ & 6 \\
\hline
\end{tabular}




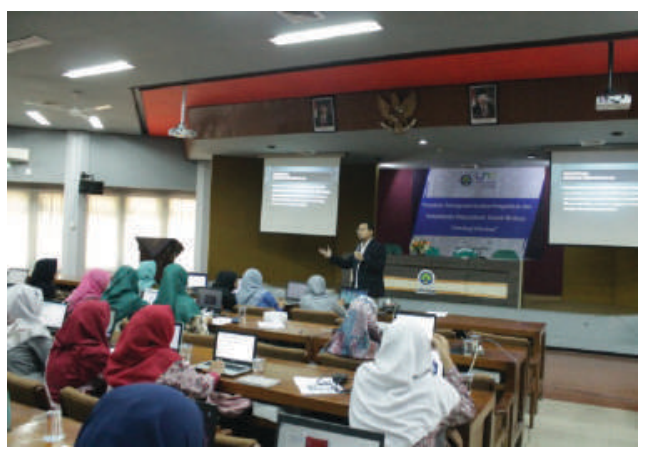

Gambar 1 Pemberian Materi Otomasi Perpustakaan

Persyaratan untuk mengikuti kegiatan pengabdian ini adalah:

1. Belum mendapatkan pelatihan sejenis utamanya terkait penggunaan teknologi informasi di perpustakaan

2. Pengelola perpustakaan tidak memiliki latar belakang formal pendidikan perpustakaan

\section{FGD Pustakawan}

Selama acara pelatihan diselenggarakan dosen terlibat aktif untuk diskusi dengan peserta yang hadir. Tujuan dari diskusi tersebut ialah untuk menggali permasalahan di lembaga masing-masing. Selama diskusi diidentifikasi masalah seperti berikut:

1. Tidak ada tenaga pengelola perpustakaan sehingga waktu proses mengerjakan kegiatan perpustakaan juga mengurusi beberapa hal yg lain selain tanggung jawab di perpustakaan

2. Tidak ada aplikasi perpustakaan

3. Semua proses pencatatan di perpustakaan dilakukan secara manual atau berbasis kertas

4. Kurangnya dukungan pemangku kepentingan
5. Tidak tersedianya ruangan perpustakaan yang memadai

6. Tidak tersedianya sarana dan prasarana yang sesuai semisal hardware

7. Bahan koleksi atau buku di perpustakaan berasal dari hadiah atau buku BOS. Anggaran tidak tersedia untuk membeli buku.

8. Minimnya program-program literasi

9. Lemahnya pemahaman terhadap konsep akuisisi perpustakaan

10. Kurangnya pelatihan sejenis yang gratis

11. Ruangan perpustakaan terlalu sempit tidak standar sesuai Standar Nasional Perpustakaan

12. Pustakawan sering dipindahtugaskan dari satu bagian ke bagian yang lain bahkan rangkap jabatan

Permasalahan diatas merupakan hal umum yang terjadi pada perpustakaan (Wicaksono, 2019), namun dengan adanya pelatihan ini maka masalah tersebut dapat diselesaikan dengan penjelasan sebagai berikut

1. Penggunaan teknologi informasi berupa aplikasi perpustakaan akan menangani permasalahan kekurangan tenaga perpustakaan, sudah tidak menggunakan cara manual karena semua tercatat pada sistem (penyelesaian masalah a,b,c, j, k) (Safii, 2019).

2. Pemberian materi manajemen perpustakaanuntukmenyelesaikan permasalahan kurangnya dukungan pemangku kepentingan, tidak tersedianya hardware dan 
software serta permasalahan bahan koleksi (penyelesaian masalah d,e dan f serta 1)

3. Pemberian materi literasi serta pendokumentasian produk literasi dalam buku ber ISBN dan pendaftaran ISBN untuk menjadikan sekolah sebagai penerbit secara gratis (menyelesaikan permasalahan $\mathrm{g}$ dan h).

\section{Pelatihan Non Teknis}

Pada tahap awal pelatihan diberikan materi terkait dengan materi

1. Gerakan Literasi Sekolah (GLS)
a. Manifesto IFLA GLS
b. Tujuan Perpustakaan Sekolah
c. Wilayah Kerjasama pustakawan dan guru
d. Keterampilan berinformasi
e. Model Literasi Informasi
f. Tahapan dalam GLS

2. Pengembangan Koleksi Dalam Pemenuhan Koleksi GLS
a. Kebijakan pengembangan koleksi
b. Daftar usulan koleksi berbasis Teknologi Informasi
c. Seleksi koleksi
d. Inventarisasi koleksiberbasis Teknologi Informasi
e. Desiderata
f. Penyiangan koleksi

Tujuan diberikan materi non teknis ialah memberikan pemahaman yang kuatpada pengelolaperpustakaan untuk dapat menyamakan visi dan misi dalam pengelolaan perpustakaan pada sekolah masing-masing. Oleh karena itu pondasi terkait standar layanan, pengadaan dan pengolahan bahan koleksi sangat penting untuk diberikan di awal pelatihan (Kamulyan \& Primasari, 2016).

\section{Pelatihan Teknologi Tepat Guna (TTG)}

$\begin{array}{clr}\text { Setelah } & \text { konsep } & \text { perpustakaan } \\ \text { dikuasai, } & \text { maka } & \text { selanjutnya }\end{array}$
diberikanlah aplikasi perpustakaan yang bernama Senayan Library Management yang sudah dikustom sehingga memberikan keuntungan lebih bagi peserta yang awam sekalipun. Diantara keunggulan dari aplikasi SLIMS yang diberikan pada peserta pelatihan yaitu : proses instalasi tidak rumit karena sudah disetting untuk portabel, terdapat menu tampilan untuk konfigurasi kartu anggota dan penggunaan E-DDC yang sudah dimasukkan dalam sistem untuk memberikan kemudahan akses klasifikasi bagi pemula.

1. Layanan bahan pustaka

a. Sistem layanan perpustakaan/ keanggotaan

b. Peminjaman, perpanjangan, dan pengembalian berbasis TI / Sirkulasi

2. Teknologi Informasi

a. Install program software SLIMS Akasia

b. Konfigurasi system SLIMS Akasia

c. Pengaturan system SLIMS Akasia

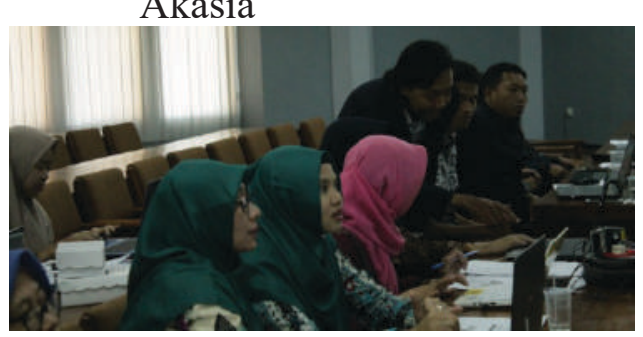

Gambar 2. Pendampingan oleh mahasiswa 
Aplikasi yang diberikan kepada pengelola perpustakaan sudah dikustom sedemikian rupa, sehingga tidak menyulitkan untuk mengimplementasikan. Dosen/ Pemateri telah melakukan perubahan pada aplikasi perpustakaan tersebut yaitu

1. Portabel

Aplikasi telah dirubah untuk dibuat portabel sehingga mudah dijalankan via flashdisk dan cocok untuk berbagai jenis laptop. 100\% peserta pelatihan sudah terinstall aplikasi dalam jangka waktu 10 menit. Sehingga porsi pelatihan dapat lanjut pada materi yang lain.

2. Penyematan EDDC

Untuk memudahkan klasifikasi telah disematkan EDDC pada menu Bibliografi sehingga akan mempermudah dan mempercepat proses entri bibliografi.

\section{Implementasi Lembaga Masing- Masing}

Sebelum pelatihan dimulai dan dibuka oleh Ketua Jurusan Sastra Indonesia Dr. Roekhan, panitia telah membagikan bahan-bahan yang dapat digunakan untuk mengelola perpustakaan sekolah nantinya jika sudah kembali ke lembaga masingmasing. Peserta pelatihan diwadahi dalam grup whatsapp untuk kemudian dapat berkonsultasi jika ada kendala di kemudian hari. Konsultasi via whatsapp grup ini merupakan cara bagi dosen untuk bermitra terus dengan pengelola perpustakaan sekolah.

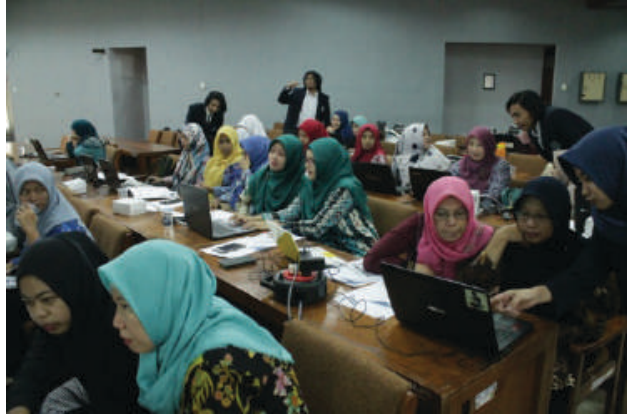

Gambar 3. Peserta antusias mengikuti pelatihan

\section{Monitoring dan Evaluasi}

Seminggu setelah pelatihan, kuisoner dibagikan kepada peserta via Google Form untuk diisi sesuai dengan kondisi sebenarnya. Monitoring dalam pelatihan ini dilakukan terus menerus pada grup whatsapp. Peserta yang memiliki kendala juga bertanya via whatsapp dan berdiskusi terkait isuisu terbaru dalam penyelenggaraan perpustakaan sekolah.

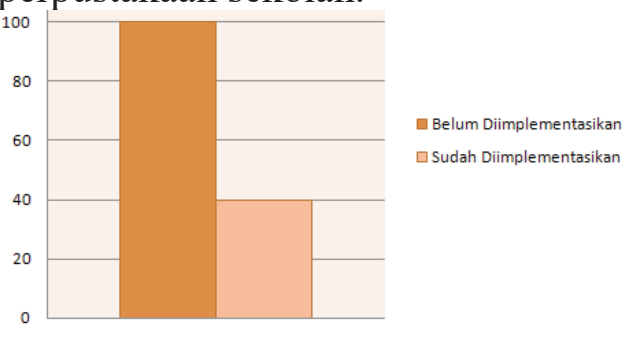

Grafik 1. Implementasi otomasi

Grafik 1 diatas menandakan
bahwa $50 \%$ peserta telah mengimplementasikan pada komputer yang tersedia di perpustakaan. Sisanya belum mengimplementasikan karena tidak ada komputer di perpustakaan, hanya laptop saat pelatihan itu pun laptop pribadi yang sudah terinstall aplikasi otomasi. Tentu ini potret permasalahan di lapangan yang harus mendapat perhatian dari pimpinan setempat. Pertanyaan dalam kuisioner 
yang lain yaitu berapa lama entri buku dilakukan. Pertanyaan ini muncul untuk mengukur apakah peserta terbiasa dengan aplikasi yang diberikan.

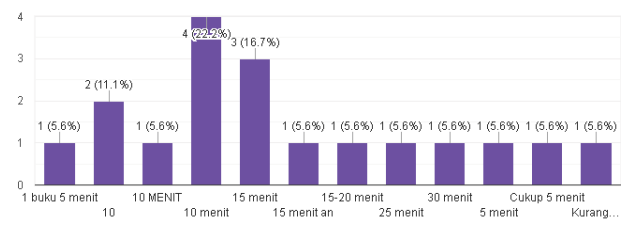

Grafik 2. Lama pengentrian bibliografi

Hasil pengukuran menunjukkan bahwa peserta membutuhkan waktu yang bervariasi. Range waktu yang dibutuhkan untuk mengentri 1 buku yaitu

Tabel 3. Waktu yang dibutuhkan

\begin{tabular}{|l|l|}
\multicolumn{1}{l}{ untuk entri 1 buku } \\
\hline $\begin{array}{l}\text { Waktu } \\
\text { (menit) }\end{array}$ & Prosentase \\
\hline 5 & 17 \\
\hline 10 & 39 \\
\hline 15 & 28 \\
\hline 20 & 6 \\
\hline 25 & 5 \\
\hline 30 & 5 \\
\hline
\end{tabular}

Dari tabel 3 diatas, nampaknya memang perlu pembiasaan setelah pelatihan selesai, namun ada beberapa faktor juga yang melatarbelakangi sehingga proses entrian menjadi lama untuk 1 buku diantaranya rangkap jabatan di sekolah, tidak ada komputer yang memadai, gagap teknologi.

Tahapan evaluasi dilakukan oleh dosen pasca pelatihan yakni tiga bulan yaitu pada Bulan Desember dengan mendatangi perpustakaan sekolah SMK 8 Malang. Sekolah ini dipilih karena perpustakaan vokasi yang kuat di bidang teknologi dan juga menurut hasil FGD dengan peserta, perpustakaan tersebut memiliki kader pustaka yang terdiri dari siswa SMK sekolah tersebut.

Dari data kuiosioner yang diisi Perpustakaan SMK 8 Malang, sudah mulai mengimplementasikan materi yang diberikan pada saat pelatihan dan Kepala Perpustakaan sekolah antusias untuk mengembangkan perpustakaan menjadi maju dan terbasis teknologi informasi.

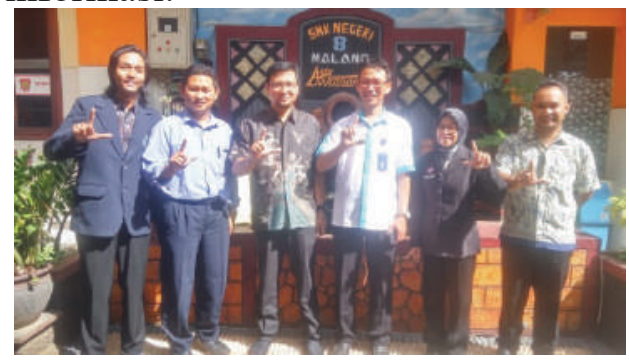

Gambar 4. Monitoring ke Perpustakaan SMK 8 Kota Malang

Saat monitoring ke Perpustakaan SMK 8 Kota Malang, pada tanggal 11 Desember 2019, dibagi menjadi 2 tim. Tim pertama bertemu dengan kepala perpustakaan sekolah dan pustakawan, tim kedua yang terdiri dari mahasiswa bertemu dengan kader pustaka. Kedua tim memiliki tanggung jawab masingmasing.

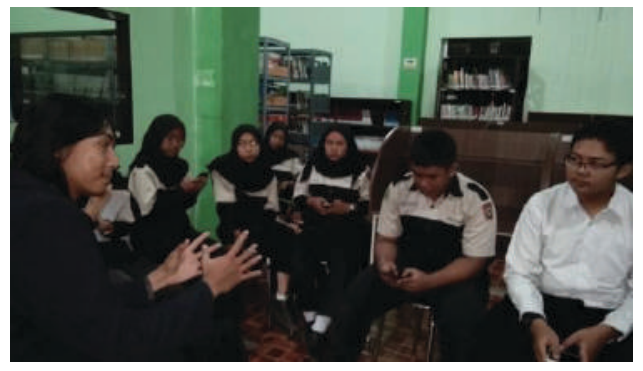

Gambar 5. Kader pustaka

Tim yang terdiri dari mahasiswa S1 Ilmu Perpustakaan bertemu dengan kader pustaka yang berjumlah 18 
anak, untuk melakukan brainstorming terhadap penyelenggaraan perpustakaan sekolah selama ini. Praktik baik diberikan kepada kader pustaka terkait pengoptimalan peran siswa dalam literasi dan juga peningkatan layanan perpustakaan kepada seluruh siswa.

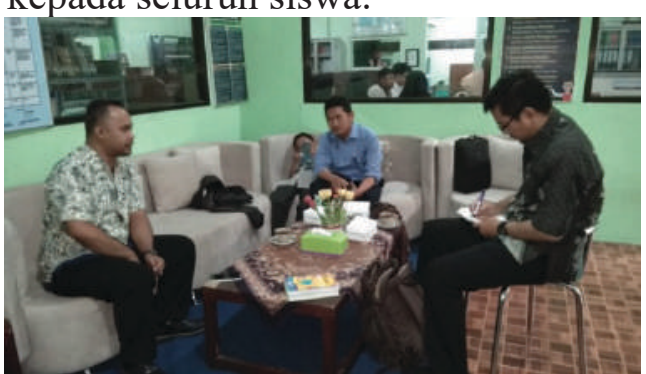

Gambar 6. Monitoring dan evaluasi oleh dosen

Saat monitoring dan evaluasi ada beberapa catatan yang diberikan yaitu:

1. Aplikasi Perpustakaan diunggah via internet, agar OPAC/Katalog Online dapat diakses secara menyeluruh

2. Akreditasi Perpustakaan Sekolah

3. Inovasi Layanan

4. Program Kerja Perpustakaan

Terkait dengan materi yang diajarkan pada pelatihan, telah diimplementasikan. Namun di Perpustakaan SMK 8, karena sudah tersedia perangkat keras, kemudian ruangan sudah tersedia maka mereka menginginkan pelatihan ditingkatkan menjadi pendampingan. Saat monitoring dan evaluasi diadakan sesi ceramah untuk memberikan penjelasan terkait akreditasi perpustakaan sekolah, langkahlangkah untuk mengunggah ke server sekolah, pendaftaran sekolah sebagai penerbit untuk mendapatkan ISBN dari perpustakaan nasional.

\section{SIMPULAN}

Kegiatan pengabdian yang diselenggarakan oleh Tim Pengabdian Masyarakat Dosen Ilmu Perpustakaan Universitas Negeri Malang dihadiri oleh 34 pengelola perpustakaan. Saat pelatihan $100 \%$ peserta telah berhasil menerapkan otomasi perpustakaan pada perangkat mereka. Namun untuk implementasi di perpustakaan sekolah $50 \%$ saja yang dapat menerapkan, sisanya terkendala oleh dukungan pimpinan setempat terkait penyediaan hardware. Perpustakaan sekolah yang memiliki dukungan lebih bahkan, dalam monitoring dan evaluasi menghendaki agar materi akreditasi dan inovasi perpustakaan di era revolusi industri 4.0 menjadi topik utama disamping materi dasar seperti otomasi perpustakaan.

\section{DAFTAR PUSTAKA}

Dewi, L., \& Suhardini, A. D. (2014). Peran Perpustakaan Dan Tenaga Perpustakaan Sekolah/ Madrasah Dalam Meningkatkan Mutu Pendidikan Di Sekolah/ Madrasah. Edulib, 4(2). https:// doi.org/10.17509/edulib. v4i2.1134

Hanafiyah, F. (2018). Literasi Lintas Kurikulum Dalam Pembelajaran Bahasa Indonesia Pada Sekolah MenengahKejuruan.Bibliotika : Jurnal Kajian Perpustakaan dan Informasi, 1(2), 41-47.

Kamulyan, M. S., \& Primasari, F. (2016). Implementasi Perpustakaan Sekolah Sebagai Sumber Belajar Dalam Meningkatkan Prestasi Belajar Siswa. Profesi Pendidikan Dasar, 1(1), 17-30. https://doi. org/10.23917/ppd.v1i1.1551 
Nahrowi, M. I. (2016). Penerapan

Standar Operasional Prosedur (Sop) Di Perpustakaan Smk Negeri 4 Malang. Tugas Akhir Prodi Perpustakaan-Fakultas Sastra.

Safii, M. (2019). Redefining The Five Laws of Library Science in the Digital Age. https://doi. org/10.2991/icclas-18.2019.7

Safii, M., Zen, Z., \& Mayesti, N. (2018). Strategi Perpustakaan Perguruan Tinggi dalam Menerapkan Library 2.0. JIPI (Jurnal Ilmu Perpustakaan dan Informasi), 3(1), 144-159. https://doi.org/10.30829/jipi. v3i1.1660

Umar, T. (2013). Perpustakaan Sekolah dalam Menanamkan Budaya Membaca. Khizanah al-Hikmah: Jurnal Ilmu Perpustakaan, Informasi, dan Kearsipan, 1(2), 123-130.

Vidiyawati, H. (2017). Manajemen layanan perpustakaan di SMA Nahdlatul Ulama 1 Gresik.

Wicaksono, M. F. (2019). Membandingkan Kompetensi Pustakawan Pendidikan dengan Pustakawan Pelatihan. Jurnal Ilmu Informasi, Perpustakaan, dan Kearsipan, 20(2). https:// doi.org/10.7454/jipk.v20i2.103 